\title{
High-resolution human KIR genotyping
}

\author{
Jonathan Downing ${ }^{1,2} \cdot$ Lloyd D'Orsogna ${ }^{1,2}$
}

Received: 11 November 2021 / Accepted: 23 December 2021 / Published online: 20 January 2022

(c) The Author(s) 2022

\begin{abstract}
Killer immunoglobulin-like receptors (KIR) regulate the function of natural killer cells through interactions with various ligands on the surface of cells, thereby determining whether natural killer (NK) cells are to be activated or inhibited from killing the cell being interrogated. The genes encoding these proteins display extensive variation through variable gene content, copy number and allele polymorphism. The combination of KIR genes and their ligands is implicated in various clinical settings including haematopoietic stem cell and solid organ transplant and infectious disease progression. The determination of KIR genes has been used as a factor in the selection of optimal stem cell donors with haplotype variations in recipient and donor giving differential clinical outcomes. Methods to determine KIR genes have primarily involved ascertaining the presence or absence of genes in an individual. With the more recent introduction of massively parallel clonal next-generation sequencing and single molecule very long read length third-generation sequencing, high-resolution determination of KIR alleles has become feasible. Determining the extent and functional impact of allele variation has the potential to lead to further optimisation of clinical outcomes as well as a deeper understanding of the functional properties of the receptors and their interactions with ligands. This review summarizes recently published high-resolution KIR genotyping methods and considers the various advantages and disadvantages of the approaches taken. In addition the application of allele level genotyping in the setting of transplantation and infectious disease control is discussed.
\end{abstract}

Keywords Killer-cell immunoglobulin receptor $($ KIR) $\cdot$ Next-generation sequencing (NGS) $\cdot$ Allele genotyping

\section{Introduction: KIR genes and their receptors}

\section{KIR structure and function}

The killer immunoglobulin-like receptor (KIR) genes, located on chromosome 19, encode a family of cell surfaceexpressed transmembrane proteins that regulate the killing of virus infected or malignant cells by natural killer (NK) cells and some T cell subsets (Wende 1999). So far, 17 genes have been described which broadly fit into two groups: inhibitory or activating, depending on whether the protein has a long (L) [2DL1, 2DL2, 2DL3, 2DL4, 2DL5A, 2DL5B, 3DL1, 3DL2, 3DL3] or short (S) [2DS1, 2DS2, 2DS3, 2DS4, 2DS5, 3DS1] cytoplasmic tail. In addition, there are

Jonathan Downing

Jonathan.Downing@health.wa.gov.au

1 Department of Clinical Immunology, PathWest, Perth, WA, Australia

2 School of Biomedical Sciences, University of Western Australia, Perth, WA, Australia two pseudogenes [2DP1, 3DP1]. Figure 1 shows a schematic of KIR protein structural organisation. The inhibitory KIR possess an immunoreceptor tyrosine-based inhibitory motif (ITIM) within their cytoplasmic domain (Blery et al. 1997), whereas activating KIR bring about activation via crosslinking with DAP12 a disulphide-bonded homodimer containing an immunoreceptor tyrosine-based activation motif (ITAM) (Lanier et al. 1998). The extracellular Ig domains are designated $\mathrm{D}_{0}, \mathrm{D}_{1}$ and $\mathrm{D}_{2}$ moving from distal to proximal to the cell membrane. The KIR3D receptors possess the $\mathrm{D}_{0}, \mathrm{D}_{1}$ and $\mathrm{D}_{2}$ domains; KIR2DL4 and 2DL5 possess $\mathrm{D}_{0}-\mathrm{D}_{2}$; all other KIR2D receptors possess $D_{1}$ and $D_{2}$. The ligands for inhibitory KIR are known to be autologous HLA-class I molecules and therefore help maintain tolerance to healthy self-tissues.

Historically, KIR genes have mostly been 'typed' to determine their presence or absence within the individual's genome. The KIR genes show a high degree of variation in individual gene content and gene copy number, but are also highly organized. The genes are located in the leucocyte receptor complex (LRC) between LILR and FCAR and sit head to tail with regular spacing. Framework genes KIR3DP1, KIR2DL4, 


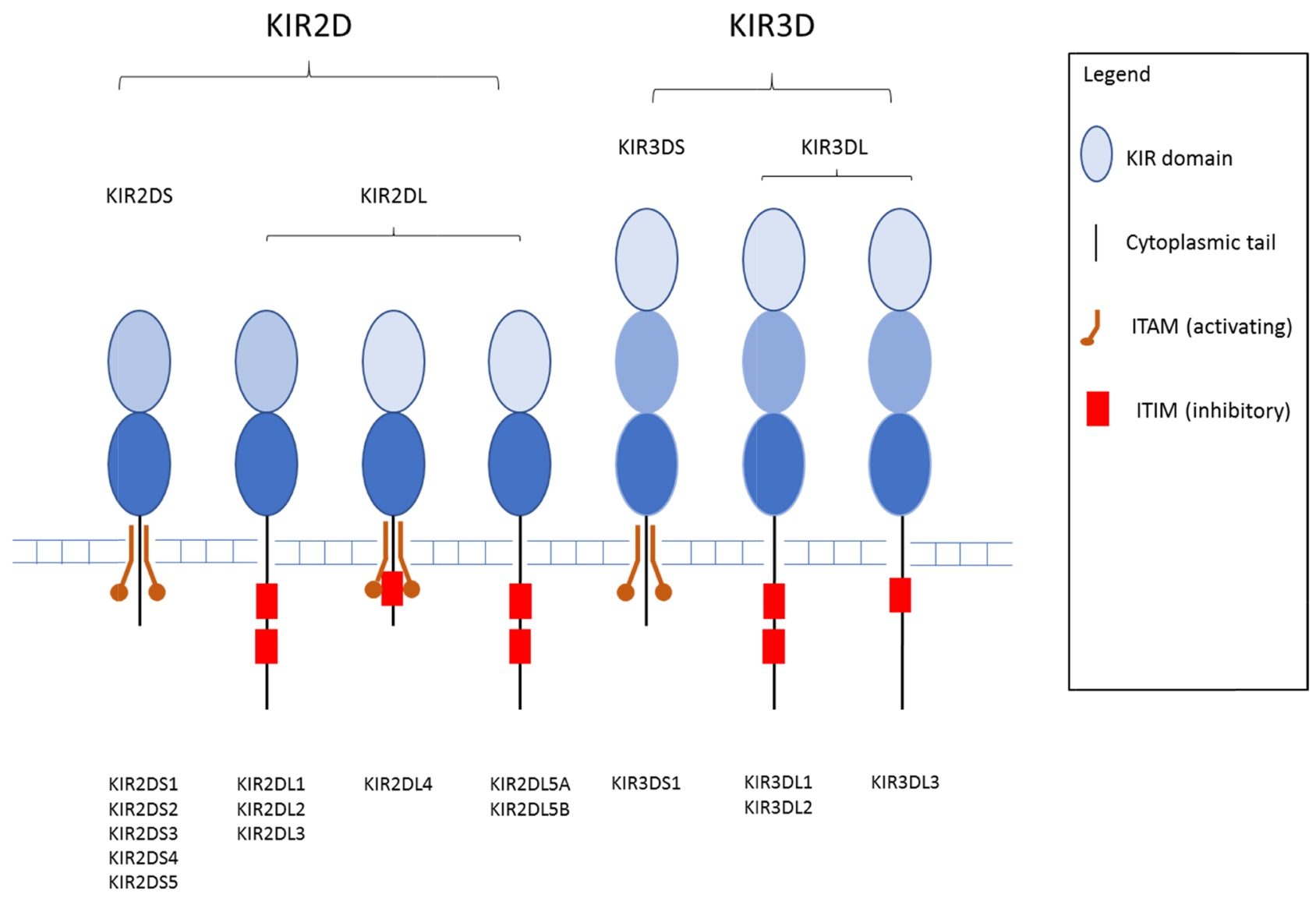

Fig. 1 Structural organisation of KIR proteins

KIR3DL2 and KIR3DL3 occur in nearly every individual and flank regions of variability (Wilson et al. 2000). At the haplotype level, KIR haplotypes are classified into two groups, namely A and B. Figure 2 shows the gene content of the A and B haplotypes. The KIR A haplotype has been defined as containing KIR3DL3, 2DL3, 2DL1, 2DL4, 3DL1, 2DS4 and 3DL2; whereas the B haplotype shows more variation and has more genes for activating receptors (Uhrberg et al. 1997). An early haplotype model theorized that the centromeric portion of KIR haplotypes segregated into five different types, whereas the telomeric portion segregated into two different types producing ten different 'prototypic' haplotypes, with further variation within these (Hsu et al. 2002). This model sees the centromeric portion as bound by the KIR3DL3 and KIR3DP1 framework genes and can possess KIR2DS2, KIR2DL2 or KIR2DL3, KIR2DL5, KIR2DS3 or KIR2DS5, KIR2DP1 and KIR2DL1. Following KIR3DP1 towards the telomeric end, framework KIR2DL4 delineates the telomeric portion which is then bound by the final framework gene KIR3DL2. This portion can then contain KIR3DL1 with either KIR2DS1 or KIR2DS4; or KIR3DS1 with either KIR2DL5 and KIR2DS3 or KIR2DL5 or KIR2DS5 and either KIR2DS1, KIR1D, or
KIR2DS4. Thus, individual gene content varies between as little as eight to as many as 14 KIR genes.

More recently, advances in gene sequencing technology has stimulated much interest in allele level KIR gene sequencing, and the genes also show a high degree of allelic polymorphism. As of December 2020, there were a total of 1532 alleles coding for 668 different proteins described in the Immuno-Polymorphism Database (Robinson et al. 2015). All KIR genes show a degree of allele polymorphism with the highest number of alleles having been described in -3DL1 (183), -3DL2 (165) and -3DL3 (228). KIR allele variation has the effect of further diversifying KIR haplotypes possessing the same set of genes (Shilling et al. 2002). A recent large study of European subjects which defined KIR genes to five-digit resolution showed that certain KIR alleles were in strong linkage disequilibrium (LD), for example KIR2DL4*00501 was in complete LD with KIR3DS1*013 and this combination was only ever found in tB01 haplotypes (Amorim et al. 2021). While KIR genes are now known to be also extremely polymorphic, there is a paucity of data associating individual KIR gene polymorphisms with disease or clinical phenotype. Allelic variation is thought to 


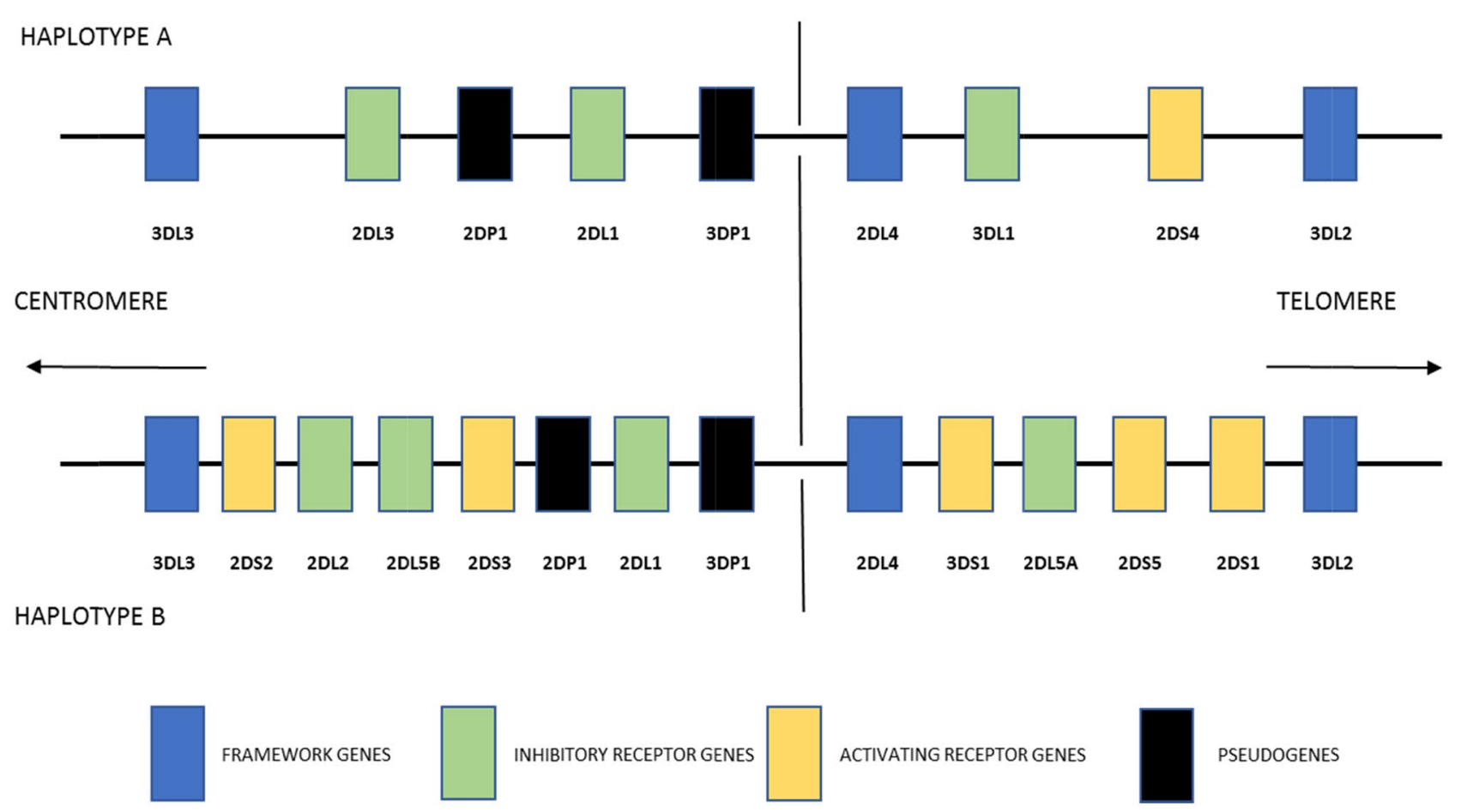

Fig. 2 Haplotype gene content

have functional consequences on the receptors generated. For example, differences in interactions have been described between KIR3DL1 and Bw4 HLA-B ligands, where the interaction of HLA-B*27:05 is weak with KIR3DL1*001 but strong with KIRDL1*002 (O'Connor et al. 2007).

\section{KIR ligands}

HLA class I molecules act as ligands for some inhibitory KIR to provide the signal to inhibit cell activation (Colonna et al. 1993; Storkus et al. 1991; Ljunggren and Kärre 1990; Moretta et al. 1993). The HLA-C molecules as ligands for KIR can be differentiated into two groups based on the amino acid residue present at position 80. An asparagine at this position occurs in the so called C1 HLA-C, whereas a lysine occurs in the $\mathrm{C} 2$, and each group comprises half of all HLA-C antigens. KIR2DL2 and KIR2DL3 are highly specific for $\mathrm{C} 1$ molecules, whereas KIR2DL1 is specific for C2. KIR3DL1 is specific of the Bw4 epitope carrying HLA-A and -B molecules (Cella et al. 1994), which comprises an isoleucine residue at position 80, whereas an asparagine is not able to signal inhibition. KIR3DL2 binds HLA-A3 and -A11 (Dohring et al. 1996). The non-classical HLA-G has been suggested as a ligand providing inhibitory signalling to KIR2DL4 by fetal-derived trophoblast cells (Rajagopalan and Long 1999). HLA-class I molecules may also act as activating ligands albeit with less avidity. One study showed KIR2DS4 to consistently bind a subset of HLA-A and -C allotypes but with a weaker binding than that shown for KIR2DL1, 2 and 3 (Graef et al. 2009). Similarly, KIR2DS5 has been shown to be a receptor with $\mathrm{C} 2$-specificity at variable levels of avidity (Blokhuis et al. 2017). There are a number of reports of KIR being specific for particular peptides bound to class I HLA, for example KIR2DS1 binding HLA-C2 in the presence of specific Epstein-Barr Virus peptides (Stewart et al. 2005) and KIR2DS2 binding to HLA-A*11:01 and a vaccinia viral peptide (Liu et al. 2014). These interactions were shown to be highly dependent on polymorphic positions in the KIR receptor suggesting that allelic variation is likely to have an effect on specificity for ligand and therefore the control of NK cell effector function. The non-classical HLA-F, localized in the endoplasmic reticulum, has been shown to be a high affinity ligand for KIR3DS1 (Garcia-Beltran 2016). Non-HLA molecules have been shown to act as activating ligands, for example, heparan sulfate/heparin glycosaminoglycans as a ligand for KIR2DL4 providing an activating signal to NK cells (Brusilovsky et al. 2013).

NK cell effector function is thought to be controlled, in part, by KIR via the 'missing self' hypothesis (Ljunggren et al. 1990; Moretta et al. 1992). NK cells are inhibited from killing target cells by the presence of their HLA class I ligands. When these ligands are missing through downregulation such as in some viral infected or tumour cells, NK cells then kill the target cell. In the setting of transplantation, lack of the complementary KIR ligand brings about graft 
rejection, or in the case of hematopoietic stem cell transplant killing of residual tumour cells and recipient $\mathrm{T}$ cells.

NK cells undergo education to acquire functional competence by way of 'licensing' by self MHC molecules. This process involves MHC-specific KIR as well as other inhibitory receptors and leads to two types of self-tolerant NK cells - licensed or unlicensed (Kim et al. 2005). Interaction between KIR and their ligands is thought to be crucial for the licensing program, and NK cells licensed through two different inhibitory receptors may become more potent in their effector functions (Yokoyama and Kim 2006). NK cells are not fully reactive against MHC class I-deficient stimuli unless their inhibitory receptors have recognized self MHC class I molecules prior to this encounter (Anfossi et al. 2006).

\section{KIR content and transplantation}

The KIR genes have been implicated in the outcome of haematopoietic stem cell transplant (HSCT). Most studies so far have focussed on gene content and the presence of certain KIR/KIR ligand mismatches and their effect on leukemic relapse. Mismatch at KIR ligands between host and donor was associated with a significantly reduced risk of relapse in haploidentical transplants in patients with acute myeloid leukaemia without leading to an increase in graft versus host disease (Ruggeri et al. 2002). Transplants using a donor with one or two KIR B haplotypes have been associated with significant improvements in overall and relapse free survival (Cooley et al. 2008). The clinical benefit of a $\mathrm{B} / \mathrm{x}$ donor was not found to depend on the presence of either KIR2DL2 or KIR2DS2, or any other B-haplotype defining KIR gene. The presence of specific activating KIR genes has been associated with better HSCT outcomes. KIR2DS1 was associated with a decreased rate of AML relapse in donors with HLA$\mathrm{C} 1 / \mathrm{C} 1$ or $\mathrm{C} 1 / \mathrm{C} 2$ (Venstrom et al. 2012); however, a recent large study failed to reproduce such an effect (Schetelig et al. 2020), highlighting the issue of often contradictory findings by studies, potentially caused by heterogeneity in transplant protocols, patient characteristics and disease states. Increased KIR alloreactivity has been shown to result in lower relapse and increased survival in unrelated cord blood allo HSCT by some groups and conversely with increased graft versus host disease and risk of death by others. These studies have led to the combination of KIR and HLA genotyping in the selection of stem cell donors. Discussion of the selection of unrelated HSCT donors based on HLA and KIR genotyping is outside of the scope of this article but is reviewed by Wright (2020).

Therefore, determining the presence or absence of KIR genes and KIR haplotype content has been a routine in acute myeloid leukaemia and clinical HSCT for many years; however, the role of individual KIR gene polymorphisms in HSCT and other immunopathologies has not been well studied. Recent sequencing advances, particularly with next-generation sequencing (NGS) technology, has therefore stimulated much interest in allelic level KIR sequencing and the possible association of KIR polymorphism with clinical disease and outcome studies.

\section{KIR genotyping}

KIR genotyping methods for the last two to three decades have focussed on determining the presence or absence of KIR genes, which goes someway to determining the haplotypes present in an individual (Fig. 2). Various approaches have been applied such as polymerase chain reaction using sequence specific primers (PCR-SSP) (Uhberg et al. 1997) and PCR using sequence-specific oligonucleotide probes (SSOP) (Crum et al. 2000). Various cloning and sequencing methods have been described (Gardiner et al. 2001) to subtype KIR gene alleles; however, these are generally low throughput and time consuming. These techniques typically focus on very limited regions of sequence and as such provide very limited amounts of information about the degree and relevance of variation at the allele level. More recently next-generation (NGS) and third-generation sequencing (TGS) methods have enabled very high throughput cost effective sequencing of much larger regions - typically whole genes, haplotypes and even whole exome sequencing, which has revolutionized gene analysis. The determination of full-length sequences, including non-coding regions has provided deeper insight into gene structure as well as degree of variation, which can now be applied to functional aspects of the proteins encoded. Short-read length NGS incorporates massively parallel sequencing of clonally amplified target DNA strands to produce millions of reads for analysis; long-read TGS is able to sequence single molecules of DNA along stretches in excess of several kilobases making it highly amenable to resolving complex gene systems with long repetitive elements and structural variations (Goodwin et al. 2016). Long-read platforms may be particularly useful for discriminating the presence of fusion KIR genes created by deletions and recombination during chromosomal rearrangements. The creation of these genes may lead to the shuffling of binding and signalling domains thus altering the response of these functional distinct gene variants (Bruijnesteijn et al. 2020). Table 1 summarizes the next-generation sequencing methods discussed below. This review will now focus on these recently developed methods in their application to high-resolution KIR gene sequencing. 
Table 1 Summary of high-resolution next-generation sequencing methods

\begin{tabular}{|c|c|c|c|c|c|c|c|c|}
\hline Method & Authors & Target type & Sequencing platform & Read length & Throughput & Error rate & Cost & Reference \\
\hline 1 & Norman et al. & $\begin{array}{l}\text { KIR-specific probe } \\
\text { capture }\end{array}$ & Illumina & Short & Medium & Low & Medium & 33 \\
\hline 2 & Maniangou et al. & $\begin{array}{l}\text { Long-range whole } \\
\text { gene multiplex PCR }\end{array}$ & Illumina & Short & Medium & Low & Low & 35 \\
\hline 3 & Closa et al. & Exon PCR & Illumina & Short & High & Low & Low & 38 \\
\hline 4 & Wagner et al. & Exon PCR & Illumina & Short & Very high & Low & Low & 39 \\
\hline 5 & Van DePasch & Whole gene PCR & Illumina & Short & Medium & Low & Medium & 29 \\
\hline 5 & Roe et al. & Fosmid libraries & PacBio & Long & Low & Medium-low & Medium & 36 \\
\hline 6 & Roe et al. & $\begin{array}{l}\text { KIR-specific probe } \\
\text { capture }\end{array}$ & PacBio & Long & Medium & Medium-low & Medium & 37 \\
\hline 7 & Bruijnesteijin et al. & $\begin{array}{c}\text { CRISPR-Cas9 } \\
\text { enrichment }\end{array}$ & $\begin{array}{l}\text { Oxford Nanopore } \\
\text { Technology } \\
\text { MinION }\end{array}$ & Very long & Low & Medium & Medium & 40 \\
\hline 8 & Downing et al. & $\begin{array}{l}\text { Long-range whole } \\
\text { gene multiplex PCR }\end{array}$ & $\begin{array}{l}\text { Oxford Nanopore } \\
\text { Technology } \\
\text { MinION }\end{array}$ & Very long & Medium & Medium & Low & $\begin{array}{l}\text { Manuscript } \\
\text { in } \\
\text { preparation }\end{array}$ \\
\hline
\end{tabular}

\section{Target capture}

A target capture sequencing approach has been described where libraries of sheared genomic DNA were enriched for the KIR region using a set of capture oligonucleotide probes prior to NGS using the Illumina platform (Norman et al. 2016). The KIR probes are non-overlapping 80-mers designed from a panel of reference KIR haplotypes representing 13 recognized KIR haplotypes. The probes are biotinylated and purified by binding to streptavidin-coated beads. DNA samples are sheared to $800 \mathrm{bp}$ fragments and individually barcoded using Illumina dual indexes before pooling. Target capture is carried out by hybridising the pooled library to the capture probes and using streptavidin beads to separate from non-target un-hybridized DNA. This workflow was used to sequence libraries from: cell lines of the International Histocompatibility Workshop Group (IHWG); families from West Africa, 15 individuals from the KhoeSan population and exome sequences from 2112 individuals from the 1000 Genomes project. Gene content had been previously determined in the IHWG samples by PCR, and KIR alleles were previously determined in the KhoeSan samples by pyrosequencing and Sanger sequencing. An inhouse bioinformatics pipeline called PING was developed which harvests KIR-specific reads for passing through modules for gene content identification, copy number determination and allele genotyping. Complete concordance was achieved with the known gene content of the IHWG samples. The analysis of 13 KIR genes in the 97 IHWG identified 144 different KIR sequences including 16 novel alleles, which were subsequently confirmed by alternative methods. KIR copy-number and allele data in the KhoeSan samples matched that previously described. From the analysis of the
1000 Genomes data, 100 novel KIR alleles were identified, which were subsequently confirmed from the genomic DNA using Sanger sequencing. One of the main benefits of the method described is the use of capture probes to obtain a sequencing target instead of PCR amplification. This abrogates PCR error and the risk of allele drop out and amplification bias. The authors state that short-read technology was chosen due to its high fidelity; however a disadvantage of short-read sequencing technology is that many of the reads would map to more than one locus due to the high degree of sequence homology in the KIR genes, these reads would then be discarded during analysis. In addition, phasing of polymorphisms could be less reliable leading to ambiguous results. The authors suggest that the method should be able to be applied to longer-read length sequencing chemistry such as Pacific Biosciences or Oxford Nanopore. This KIR genotyping workflow was recently employed to analyse a cohort of 2130 healthy individuals of European descent (Amorim et al. 2021). This study has revealed far more gene content and structure variation than any other work to date, particularly among the framework genes, with, for example, more than $6 \%$ of individuals carrying a deletion or duplication of KIR2DL4. The PING pipeline has recently been refined and updated (Marin et al. 2021), improving the throughput and enhancing copy number determination. Read misalignment with the highly homologous KIR2DS1 and KIR2DL1 genes was also improved as was the need to interpret unresolved genotypes. Even with these improvements, this study clearly highlights the difficulty in assigning reads by a bioinformatic pipeline. Misaligned reads were most frequently seen in the KIR3DP1 gene, which received reads originating from KIR3DL3, KIR3DL2, KIR2DP1 and KIR2DL4. Pairing of genes where misaligned reads were 
frequently seen was identified as KIR2DL1 and KIR2DS1 and KIR2DL2 and KIR2DS2. The use of short-read technology almost certainly contributed to the difficulty in aligning reads, for example, in this study, it was observed that $82 \%$ of distinct 150 -mers were shared between KIR2DL5A and KIR2DL5B. It will be interesting to see this workflow applied to long-read technology.

\section{Long-range PCR}

A long-range PCR based assay, followed by Illumina NGS, was described using six primers in a single multi-plex PCR mixture to amplify all full length KIR genes (Maniangou et al. 2017). The amplicons generated varied in size from 4 to $5 \mathrm{~kb}$ for KIR3DP1 to 9 to $17 \mathrm{~kb}$ for all other genes. Library preparation and dual indexing was performed for sequencing on a MiSeq instrument. A manual bioinformatics pipeline was employed to map sequencing reads to a reference sequence; exon sequences were extracted and compared for polymorphic bases with those contained in the IPD-KIR database. Two different bioinformatic pipelines were then employed for determining KIR allele assignment. This workflow was applied to 30 IHWG DNA samples as a validation. In all 30 samples good coverage was achieved with an average coverage of $316.55 \mathrm{X}$. Allele assignment was obtained for all loci for most samples. The results were compared to those obtained by Norman's capture-based NGS method with the finding that $100 \%$ of allele assignments at the three digit level were concordant in 11 KIR genes $(n=110$ alleles); semi-discordance, where one allele of a heterozygous typing was different, was found in ten alleles across six loci; and fully discordant results were found in two cases. The authors state that the described method is easily implemented and possibly cheaper than a capture-based method but stressed the requirement for good quality DNA, high fidelity Taq polymerase and reliable library preparation.

\section{Amplicon-based exon sequencing}

A different approach using PCR was described where the KIR genes were amplified to produce two amplicons, one covering exons 1 to 5 and the other covering exons 6 to 9 (Closa et al. 2018). A total of eight primers were used in a single multiplex mixture along with eight primers for class I HLA genes. The GENDX NGSgo kit was used to prepare indexed libraries for sequencing on the MiSeq. This workflow was validated with 186 DNA samples made up of 30 IHWG samples with previously determined highresolution KIR genotypes and 156 local DNA samples previously typed for gene content by PCR-SSO. Analysis of the KIR sequences was performed by mapping reads to hg 19 which were visualized with commercial bioinformatics software. KIR gene content was determined using four gene specific virtual probes per locus, which were used to find exact matches in FASTQ sequence files. KIR gene content results were found to be $97.84 \%$ concordant with the PCR-SSO result. It was estimated that around 250 samples could be analysed in a single MiSeq run using this method. Although not intended for KIR allele determination, it was suggested by the authors that this approach could be used for allele level typing when a suitable allele calling programme becomes available.

A very high throughout short amplicon PCR NGS strategy was described targeting KIR exons 3-5 and 7-9 in four separate reactions (Wagner et al. 2018). Subsequently, the reactions were pooled for each sample and index and sequencing adaptors added. Then a total of 384 samples were combined with pools of HLA, blood group and CCR5 genes for sequencing on the Illumina HiSeq2500. The inhouse bioinformatics pipeline consisted of determining gene content and copy number and then allele assignment with results given as a genotype list (GL) string. The method was validated using DNA from 93 IHWG samples and a reference set of 360 samples previously typed for KIR at the allelic level. In the IHWG samples, 413 genes were identified correctly as being absent, 224 were identified as being present but no allele called due to either a novel nucleotide or failure to meet quality criteria. Finally, 851 genes were typed at the allelic level and all but three were concordant with the previously reported result. The workflow has been used to type 1.8 million potential HSCT donors at the allelic level providing a useful insight into KIR allele frequencies. Differences were seen in the number of alleles present for each gene. Limited diversity was observed in the activating KIR genes with a single allele occurring at high frequency for some genes. Greater diversity was seen in the inhibitory KIR with evenly distributed frequencies. In a subset of 185,170 samples 5203 sequences were identified with novel positions compared to the reference database highlighting the degree to which diversity in these genes is only just beginning to be revealed. While this method demonstrates the power of high throughput NGS workflow with an impressive number of samples genotyped at very low cost, due to the incomplete coverage of the genes ambiguous results are encountered. This method has been employed recently to identify a set of 551 KIR allele group haplotypes representing 21 KIR copy number haplotypes helping to broaden the understanding of the KIR genes (Solloch et al. 2020).

\section{Commercial whole gene PCR}

A PCR-based method was developed for commercial use by the sequencing technology company GenDX (van de Pasch et al. 2018). Nine of the 17 KIR genes were targeted in several group specific PCR mixtures which were then subjected to limited group pooling and then library preparation 
for Illumina MiSeq sequencing. Resulting sequencing data was analysed using the commercially available NGSEngine software. The authors noted the challenges of KIR copy number variation and high degree of homology hampering data analysis; however, the majority of samples were able to be typed unambiguously.

\section{Long-range sequencing using PacBIO platform}

A study from the Centre for International Blood and Marrow Transplant Research (CIBMTR) looking at whole KIR haplotypes described a method using long-read technology on the PacBio platform (Roe et al. 2017). Pools of fosmid libraries targeted for KIR sequence content were constructed to span the entire KIR region in eight individuals. Full lengths of KIR locus inserts were isolated from the linearized fosmids and subjected to SMRT sequencing on the PacBio RS II. Using this approach, continuous reads of around $40 \mathrm{~kb}$ allowed the unambiguous assembly of two KIR haplotypes for each of the eight diploid samples. Nine distinct haplotype structures were identified in the study samples including four haplotypes not previously described. This method has recently been updated for application to population scale and clinical studies (Roe et al. 2020), replacing the technically demanding fosmid library creation with capture probe enrichment of long fragments of KIR targets which are subsequently sequenced by PacBio. Again, fully sequenced and phased diploid KIR haplotypes with fully annotated alleles were determined.

\section{CRISPR-Cas9 target enrichment}

A CRISPR-Cas9 target enrichment method followed by Oxford Nanopore sequencing has recently been described (Bruijnesteijn et al. 2021), where guiding crRNA were designed to direct Cas9 endonuclease to cleave large overlapping DNA segments of the entire KIR region. Cleaved target sites were left with an available phosphate group which was utilized for dA-tailing and then ligation to nanopore sequencing adaptors. Nanopore sequencing relies on a signal change in the electric current passed across a synthetic nanopore as nucleotides pass through the pore. The signal produced is subsequently converted into nucleotide sequence resulting in reads potentially in excess of $100-\mathrm{kb}$ long. This method was used to generate fully phased haplotypes in two subject DNAs, with a third fully phased except for one KIR gene.

\section{Whole KIR gene sequencing on nanopore platform}

Our group is developing a full gene PCR amplicon-based method using the Oxford Nanopore Technology MinION platform. Using previously published PCR primers, all KIR genes are amplified and then subjected to a straightforward library preparation involving end repair, barcoding, pooling of around 24 samples, adaptor ligation and loading on to a MinION flow cell. The major challenge that exists for all the described methods is the accurate analysis of genes with a high degree of sequence homology, particularly where throughput gains of multiplexing and sample pooling are highly desirable. Initial analysis of the long-read length output using GENDx NGSEngine in a set of IHWG DNA samples shows promise. This method will be published separately once fully validated.

\section{The use of high-resolution allele level KIR typing in health and disease}

\section{KIR in HSCT}

High-resolution KIR genotyping has been employed in a growing number of studies into the allelic variation present in the KIR gene family. KIR gene allelic variation has been linked with the outcome of HSCT and solid organ transplant illustrating the need for further study of these genes at this level. Allelic variation in KIR genes allows for the characterisation of individuals by differing levels of expression, with high and low expression alleles providing stronger and weaker inhibitory signals. Donors with low inhibition KIRKIR ligand combinations have been associated with lower relapse and higher survival, whereas combinations with higher expression, higher inhibitory activity were associated with higher relapse (Schaffer and Hsu 2016). Bari et al. have shown that allelic polymorphism in KIR2DL1 affects overall recipient survival and progression-free survival in pediatric allogeneic HSCT patients (Bari et al. 2013). Patients who received grafts with the functionally stronger KIR2DL1 allele with arginine at amino acid position 245 (KIR2DL1-R245) had better survival and lower cumulative incidence of disease progression than those patients who received a donor graft that contained only the functionally weaker KIR2DL1 allele with cysteine at the same position (KIR2DL1-C245). KIR3DL1 alleles have been segregated based on patterns of strong $(* 001, * 002)$, weak $(* 005, * 007)$ or lack $(* 004)$ inhibition by target cells with HLA-B subtypes and in AML patients who received HLA-compatible allografts, donor-recipient KIR3DL1/HLA-B subtype combinations that demonstrate weak or no inhibition were associated with significantly lower relapse and higher survival compared with strong inhibition combinations (Boudreau et al. 2017). A pilot study found that weak or non-inhibiting KIR3DL1 subtype donors could be identified for $93 \%$ of 211 patients who had more than one donor available, and that patients with weak or non-inhibiting KIR3DL1/HLA-B partnerships experienced higher 2-year disease free survival 
(Schaffer et al. 2016). Subsequently KIR allele subtyping has been shown to be feasible in prospective HSCT donor selection where KIR3DL1 alleles of potential donors were differentiated into high and low expression groups (Schaffer et al. 2021). Donors were thus assessed for KIR advantage with strength of inhibition of donor KIR3DL1 by recipient HLA-B as the priority, followed by presence of HLA-C1/ KIR2DS1 and centromeric KIR haplotype content. In AML patients transplanted with donors with KIR2DL1*003 and KIR2DL3*001, seen in Cen AA individuals, a more consistent and effective NK cell response was seen which led to a significant reduction in the rate of relapse after T-replete haplo-identical HSCT (Dubreuil et al. 2020). A recent study has shown that characterising individuals for the presence of a particular B haplotype defined by allele level genotyping showed a trend to significance for protecting from relapse (Guethlein et al. 2021). In this study, allele level typing was used to differentiate Cen B/B haplotypes into Cen B01 and Cen B02, the latter of which was implicated with relapse protection.

\section{KIR in solid organ transplantation}

The role of NK cells has been studied in the solid organ transplant setting. NK cells are known to infiltrate kidney allografts and occur at a higher frequency in the peripheral blood of patients with acute graft rejection. A role for inhibitory KIR-KIR ligand has been shown in the increased risk of chronic rejection and reduction long-term graft survival (Littera et al. 2017). KIR2DS4 and KIR2DS5 have been implicated in the outcome of renal transplantation in patients with glomerular nephritis (Nowak et al. 2012). KIR2DS4 was more frequent in patients with acute graft rejection, whereas KIR2DS5 was associated with decreased rejection. Interindividual differences in KIR and HLA class I ligand genotypes associated with differences in NK cell reactivity impact donor-specific antibody-mediated NK cell antibody dependant cell-mediated cytotoxicity in organ allografts (Rajalingam 2016). In addition, differences have been shown in the number of KIR2D expressing $\mathrm{CD} 8^{+} \mathrm{T}$ cells between liver transplant recipients with and without acute rejection, suggesting a role for KIR receptors in liver allograft outcomes (Lopez-Alvarez et al. 2011).

\section{KIR in HIV infection and control}

In the context of infectious disease, KIR molecules have been shown to exhibit an effect in a variety of settings. The protection from HIV disease progression was shown to be associated with the presence of KIR3DL1 and its ligand HLA-B Bw4, particularly where the 80I is present (Martin and Gao et al. 2002). More recently, in individuals possessing HLA-B*57, a variant of the KIR3DL1 molecule has been shown to be associated with elite control of viral load and delay in disease progression (Martin and Naranbhai et al. 2018). The presence of a valine residue at position 47 of the KIR molecule was significantly higher in elite controllers of the disease. Similarly, KIR2DL3 has been shown to be protective against Hepatitis C virus whereas KIR2DL1 has been associated with recurrent human cytomegalovirus infection.

\section{8th IHIWS workshop: KIR genotyping project}

The 18th IHIWS Workshop taking place in Amsterdam, the Netherlands, May 2022 includes a project for sequencing full length KIR genotypes. Laboratories interested in KIR are encouraged to participate and submit samples for KIR sequencing (https://www.ihiw18.org/component-immunogenetics/ kir-typing/).

The goal of this project is to characterize the nature and extent of KIR allelic diversity across human populations using next-generation sequencing (NGS). Participating labs will perform high-resolution KIR genotyping in unrelated individuals from diverse populations. Studies in families will also be conducted in order to define phased KIR haplotypes through segregation analysis.

\section{Conclusion}

Next-generation and third-generation sequencing methods are able to generate a massive amount of sequencing data in a high throughput and cost-effective manner. The super high resolution of sequencing able to be performed will provide a detailed view of the KIR gene and haplotype structures. This knowledge can then be carried into studies of how allelic variation might affect NK cell function, outcomes in HSC and solid organ transplantation and the progression of infectious disease. Such studies are likely to provide a greater insight into how KIR molecules interact with their ligands and how variation affects affinity and specificity of the KIR molecules for their targets.

Author contribution J. D. had the idea for the review topic, performed the literature review and drafted the article. L. D'O. critically revised the work.

Funding Open Access funding enabled and organized by CAUL and its Member Institutions. 


\section{Declarations}

Conflict of interest The authors declare no competing interests.

Open Access This article is licensed under a Creative Commons Attribution 4.0 International License, which permits use, sharing, adaptation, distribution and reproduction in any medium or format, as long as you give appropriate credit to the original author(s) and the source, provide a link to the Creative Commons licence, and indicate if changes were made. The images or other third party material in this article are included in the article's Creative Commons licence, unless indicated otherwise in a credit line to the material. If material is not included in the article's Creative Commons licence and your intended use is not permitted by statutory regulation or exceeds the permitted use, you will need to obtain permission directly from the copyright holder. To view a copy of this licence, visit http://creativecommons.org/licenses/by/4.0/.

\section{References}

Amorim LM, August DA, Nemat-Gorgani N, Montero-Martin G, Marin WM, Shams H, Dandekar R, Caillier S, Parham P, Fernandez-Viña MA, Oksenberg JR, Norman PJ, Hollenbach JA (2021) High resolution characterization of KIR genes in a large North American cohort reveals novel details of structural and sequence diversity. Front Immunol 12:674778-674778

Anfossi N, Anfre P, Guia S, Falk C, Roetynck S, Stewart C, Breso V, Frassati C, Reviron D, Middleton D, Romagne F, Ugolini S, Vivier E (2006) Human NK cell education by inhibitory receptors for MHC class I. Immunity 25:331-342

Bari R, Rujkijyanont P, Sullivan E, Kang G, Turner V, Gan K, Leung (2013) Effect of donor KIR2DL1 allelic polymorphism on the outcome of pediatric allogeneic hematopoietic stem-cell transplantation. J Clin Oncol 31:3782-3790

Bléry M, Delon J, Trautmann A, Cambiaggi A, Olcese L, Biassoni R, Moretta L, Chavrier P, Moretta A, Daëron M, Vivier E (1997) Reconstituted killer cell inhibitory receptors for major histocompatibility complex class i molecules control mast cell activation induced via immunoreceptor tyrosine-based activation motifs. J Biol Chem 272(14):8989-8996

Blokhuis J, Hilton H, Guethlein L, Norman P, Nemat-Gorgani N, Nakimuli A, Chazara O, Moffett A, Parham P (2017) KIR2DS5 allotypes that recognize the $\mathrm{C} 2$ epitope of HLA-C are common among Africans and absent from Europeans. Immun Inflamm Dis 5:461-468

Boudreau JE, Giglio F, Gooley TA, Stevenson PA, Le Luduec J-B, Shaffer BC, Rajalingam R, Hou L, Hurley CK, Noreen H, Reed EF, Yu N, Vierra-Green C, Haagenson M, Malkki M, Petersdorf EW, Spellman S, Hsu KC (2017) KIR3DL1/HLA-B subtypes govern acute myelogenous leukemia relapse after hematopoietic cell transplantation. J Clin Oncol 35(20):2268-2278

Bruijnesteijn J, de Groot NG, Bontrop RE (2020) The genetic mechanisms driving diversification of the KIR gene cluster in primates. Front Immunol 11:582804

Bruijnesteijn J, van der Wiel M, de Groot NG, Bontrop RE (2021) Rapid characterization of complex killer cell immunoglobulinlike receptor (KIR) regions using Cas9 enrichment and nanopore sequencing. Front Immunol 12:722181-722181

Brusilovsky M, Cordoba M, Rosental B, Hershkovitz O, Andrake MD, Pecherskaya A et al (2013) Genome-wide siRNA screen reveals a new cellular partner of NK cell receptor KIR2DL4: heparan sulfate directly modulates KIR2DL4-mediated responses. J Immunol 191:5256-5267
Cella M, Longo A, Battista Ferrara G, Strominger JL, Colonna M (1994) NK3-specific natural killer cells are selectively inhibited by Bw4positive HLA alleles with isoleucine 80. J Exp Med 180(4):1235-1242

Closa L, Vidal F, Herrero MJ, Caro JL (2018) Design and validation of a multiplex KIR and HLA class i genotyping method using next generation sequencing. Front Immunol 9:2991-2991

Colonna M, Borsellino G, Falco M, Ferrara GB, Strominger JL (1993) HLA-C is the inhibitory ligand that determines dominant resistance to lysis by NK1- and NK2-specific natural killer cells. Proc Natl Acad Sci - PNAS 90(24):12000-12004

Cooley S, Trachtenberg E, Bergemann TL, Saeteurn K, Klein J, Le CT, Marsh SGE, Guethlein LA, Parham P, Miller JS, Weisdorf DJ (2008) Donors with group B KIR haplotypes improve relapse free-survival after unrelated hematopoietic cell transplantation for acute myelogenous leukemia. Blood 113:726-732

Crum KA, Logue SE, Curran MD, Middleton D (2000) Development of a PCR-SSOP Approach capable of defining the natural killer cell inhibitory receptor (KIR) gene sequence repertoires: a PCRSSOP approach for defining KIR gene sequence repertoires. Tissue Antigens 56(4):313-326

Dohring C, Scheidegger D, Samaridis J, Cella M, Colonna M (1996) A human killer inhibitory receptor specific for HLA-A1,2. J Immunol 156(9):3098-3101

Dubreuil L, Maniangou B, Chevallier P, Quemener A, Legrand N, Bene MC, Willem C, David G, Alizadeh M, Makanga DR, Cesbron A, Gendzekhadze K, Gagne K, Retiere C (2020) Centromeric KIR AA Individuals harbor particular KIR alleles conferring beneficial NK cell features with implications in haplo-identical hematopoietic stem cell transplantation. Cancers 12(12):3595-4013

Garcia-Beltran W, Holzemer A, Martrus G, Chung A, Pacheco Y, Simoneau C, Rucevic M, Lamothe-Molina P, Pertel T, Kim T, Dugan H, Alter G, Dechanet-Merville J, Jost S, Carrington M, Atfeld M (2016) Open conformers of HLA-F are high-affinity ligands of the activating NK-cell receptor KIR3DS1. Nat Immunol 17:1067-1074

Gardiner CM, Guethlein LA, Shilling HG, Pando M, Carr WH, Rajalingam R, Vilches C, Parham P (2001) Different NK cell surface phenotypes defined by the DX9 antibody are due to KIR3DL1 gene polymorphism. J Immunol 166(5):2992-3001

Goodwin S, McPherson JD, McCombie WR (2016) Coming of age: ten years of next-generation sequencing technologies. Nat Rev Genet 17(6):333-351

Graef T, Moesta AK, Norman PJ, Abi-Rached L, Vago L, Older Aguilar AM, Gleimer M, Hammond JA, Guethlein LA, Bushnell DA, Robinson PJ, Parham P (2009) KIR2DS4 is a product of gene conversion with KIR3DL2 that introduced specificity for HLA-A11 while diminishing avidity for HLA-C. J Exp Med 206(11):2557-2572

Guethlein LA, Beyzaie N, Nemat-Gorgani N, Wang T, Ramesh V, Marin WM, Hollenbach JA, Schetelig J, Spellman SR, Marsh SGE, Cooley S, Weisdorf DJ, Norman PJ, Miller JS, Parham P (2021) Following transplantation for acute myelogenous leukemia, donor KIR Cen B02 better protects against relapse than KIR Cen B01. J Immunol 206(12):3064-3072

Hsu KC, Chida S, Geraghty D, Dupont B (2002) The killer cell immunoglobulin-like receptor (KIR) genomic region: geneorder, haplotypes and allelic polymorphism. Immunol Rev 190:40-52

Kim S, Poursine-Laurent J, Truscott S, Lybarger L, Song Y, Yang L, French A, Sunwoo J, Lemieux S, Hansen T, Yokoyama W (2005) Licensing of natural killer cells by host major histocompatibility complex class I molecules. Nature 436:709-713

Lanier LL, Corliss BC, Wu J, Leong C, Phillips JH (1998) Immunoreceptor DAP12 bearing a tyrosine-based activation motif is involved in activating NK cells. Nature 391(6668):703-707 
Littera R, Piredda G, Argiolas D, Lai S, Congeddu E, Ragatzu P, Melis M, Carta E, Michittu MB, Valentini D, Cappai L, Porcella R, Alba F, Serra M, Loi V, Maddi R, Orrù S, La Nasa G, Caocci G, Cusano R, Arras M, Frongia M, Pani A, Carcassi C (2017) KIR and their HLA class I ligands: two more pieces towards completing the puzzle of chronic rejection and graft loss in kidney transplantation. PLoS One 12(7):e0180831-e0180831

Liu J, Xiao Z, Ko H, Shen M, Ren E (2014) Activating killer cell immunoglobulin-like receptor 2DS2 binds to HLA-A*11. Proc Natl Acad Sci - PNAS 111(7):2662-2667

Ljunggren H, Kärre K (1990) In Search of the "missing Self”: MHC molecules and NK cell recognition. Immunol Today 11(7):237-244

López-Álvarez MR, Campillo JA, Legaz I, Blanco-García RM, SalgadoCecilia G, Bolarín JM, Gimeno L, Gil J, García-Alonso AM, Muro M, Álvarez-López MR, Miras M, Minguela A (2011) Divergences in KIR2D+ natural killer and KIR2D+CD8+ T-cell reconstitution following liver transplantation. Hum Immunol 72:229-237

Maniangou B, Legrand N, Alizadeh M, Guyet U, Willem C, David G, Charpentier E, Walencik A, Retière C, Gagne K (2017) Killer immunoglobulin-like receptor allele determination using nextgeneration sequencing technology. Front Immunol 8:547

Marin WM, Dandekar R, Augusto DG, Yusufali T, Heyn B, Hofmann J, Lange V, Sauter J, Norman PJ, Hollenbach JA, Ay F (2021) High-throughput interpretation of killer-cell immunoglobulin-like receptor short-read sequencing data with PING. PLoS Comput Biol 17(8):e1008904-e1008904

Martin MP, Gao X, Lee J, Nelson GW, Detels R, Goedert JJ, Buchbinder S, Hoots K, Vlahov D, Trowsdale J, Wilson M, O'Brien SJ, Carrington M (2002) Epistatic interaction between KIR3DS1 and HLA-B delays the progression to AIDS. Nat Genet 31(4):429-434

Martin MP, Naranbhai V, Shea PR, Qi Y, Ramsuran V, Vince N, Gao X, Thomas R, Brumme Z, Carlson JM, Wolinsky SM, Goedert JJ, Walker BD, Segal FP, Deeks SG, Haas DW, Migueles SA, Connors M, Michael N, Fellay J, Gostick E, Llewellyn-Lacey S, Price DA, Lafont BA, Pymm P, Saunders PM, Widjaja J, Wong SC, Vivian JP, Rossjohn J, Brooks AG, Carrington M (2018) Killer cell immunoglobulin-like receptor 3DL1 variation modifies HLA-B57 protection against HIV-1. J Clin Investig 128(5): 1903-1912

Moretta L, Ciccone E, Moretta L, Hoglund P, Ohlen C, Karre K (1992) Allorecognition by NK cells: non-self or no self? Immunol Today 13:300

Moretta A, Vitale M, Bottino C, Orengo AM, Morelli L, Augugliaro R, Barbaresi M, Ciccone E, Moretta L (1993) P58 molecules as putative receptors for major histocompatibility complex (MHC) class i molecules in human natural killer (NK) cells. Anti-P58 antibodies reconstitute lysis of MHC class i-protected cells in NK clones displaying different specificities. J Exp Med 178:597

Norman PJ, Hollenbach JA, Nemat-Gorgani N, Marin WM, Norberg SJ, Ashouri E, Jayaraman J, Wroblewski EE, Trowsdale J, Rajalingam R, Oksenberg JR, Chiaroni J, Guethlein LA, Traherne JA, Ronaghi M, Parham P (2016) Defining KIR and HLA class I genotypes at highest resolution via high-throughput sequencing. Am J Hum Genet 99:375

Nowak I, Magott-Procelewska M, Kowal A, Miazga M, Wagner M, Niepiekło-Miniewska W, Kamińska M, Wiśniewski A, Majorczyk E, Klinger M, Łuszczek W, Pawlik A, Płoski R, Barcz E, Senitzer D, Kuśnierczyk P, Perez-Martinez A (2012) Killer immunoglobulinlike receptor (KIR) and HLA genotypes affect the outcome of allogeneic kidney transplantation. PLoS One 7:e44718

O'Conner G, Guinan K, Cunningham R, Middleton D, Parham P, Gardiner C (2007) Functional polymorphism of the KIR3DL1/S1 receptor on human NK Cells. J Immunol 178:235-241

Rajagopalan S, Long EO (1999) A human histocompatibility leukocyte antigen (HLA)-G-specific receptor expressed on all natural killer cells. J Exp Med 189:1093-1100
Rajalingam R (2016) The impact of HLA class I-specific killer cell immunoglobulin-like receptors on antibody-dependent natural killer cell-mediated cytotoxicity and organ allograft rejection. Front Immunol 7:585

Robinson J, Halliwell JA, Hayhurst JD, Flicek P, Parham P, Marsh SGE (2015) The IPD and IPD-IMGT/HLA Database: allele variant databases. Nucleic Acids Res 43:D423-D431

Roe D, Vierra-Green C, Pyo CW, Eng K, Hal R, Kuang R, Spellman S, Ranade S, Geraghty DE, Maiers M (2017) Revealing complete complex KIR haplotypes phased by long-read sequencing technology. Genes Immun 18:127

Roe D, Williams J, Ivery K, Brouckaert J, Downey N, Locklear C, Kuang R, Maiers M (2020) Efficient sequencing, assembly, and annotation of human KIR haplotypes. Front Immunol 11:582927

Ruggeri L, Capanni M, Urbani E, Perruccio K, Shlomchik WD, Tosti A, Posati S, Rogaia D, Frassoni F, Aversa F, Martelli MF, Velardi A (2002) Effectiveness of donor natural killer cell alloreactivity in mismatched hematopoietic transplants. Science 295:2097-2300

Schaffer BC, Hsu KC (2016) How important is NK alloreactvity and KIR in allogeneic transplantation? Best Pract Res Clin Haematol 29:351-358

Shaffer BC, Heller G, Le Luduec J, Vahradian J, Perales M, Giralt SA, Tamari R, Gyurkocza B, Jakubowski AA, Papadopoulos EB, Boudreau JE, Kernan NA, Hsu KC (2016) Selection of unrelated allogeneic hematopoietic cell donors based on KIR3DL1 allotypes is feasible and results in improved disease-free survival in transplant recipients with MDS and AML. Blood 128:990

Shaffer BC, Le Luduec J, Park S, Devlin S, Archer A, Davis E, Cooper C, Nhaissi M, Suri B, Wells D, Tamari R, Papadopoulos E, Jakubowski AA, Giralt S, Hsu KC (2021) Prospective KIR genotype evaluation of hematopoietic cell donors is feasible with potential to benefit patients with AML. Blood Adv 5:2003-2011

Schetelig J, Baldauf H, Heidenreich F, Massalski C, Frank S, Sauter J, Stelljes M, Ayuk FA, Bethge WA, Bug G, Klein S, Wendler S, Lange V, de Wreede LC, Fürst D, Kobbe G, Ottinger HD, Beelen DW, Mytilineos J, Fleischhauer K, Schmidt AH, Bornhauser M (2020) External validation of models for KIR2DS1/KIR3DL1-informed selection of hematopoietic cell donors fails. Blood 135:1386-1395

Shilling HG, Guethlein LA, Cheng NW, Gardiner CM, Rodriguez R, Tyan D, Parham P (2002) Allelic polymorphism synergizes with variable gene content to individualize human KIR genotype. J Immunol 168:2307-2315

Solloch U, Schefzyk D, Schaefer G, Massalski C, Kohler M, Pruschke J, Heidl A, Schetelig J, Schmidt AH, Lange V, Sauter J (2020) Estimation of German KIR allele group haplotype frequencies. Front Immunol 11:429

Stewart C, Laugier-Anfossi F, Vély F, Saulquin X, Riedmuller J, Tisserant A, Gauthier L, Romagne F, Ferracci G, Arosa F, Moretta A, Sun P, Ugolini S, Vivier E (2005) Recognition of peptide-MHC class I complexes by activating killer immunoglobulin-like receptors. Proceedings of the National Academy of Sciences - PNAS 102(37):13224-13229

Storkus WJ, Salter RD, Alexander J, Ward FE, Ruiz RE, Cresswell P, Dawson JR (1991) Class I-induced resistance to natural killing: identification of nonpermissive residues in HLA-A2. Proceedings of the National Academy of Sciences - PNAS 88:5989

Uhrberg M, Valiante NM, Shum BP, Shilling HG, Lienert-Weidenbach K, Corliss B, Tyan D,Lanier LL, Parham P (1997) Human diversity in killer cell inhibitory receptor genes. Immunity (Cambridge, Mass.) 7:753-763

van de Pasch LA, van Ham K, Vendelbosch S, Penning MT, Rozemuller EH (2018) OR36 NGS allele-level typing strategy for nine KIR genes. Hum Immunol 79:42

Venstrom JM, Pittari G, Gooley TA, Chewning JH, Spellman S, Haagenson M, Gallagher MM, Malkki M, Petersdorf E, Dupont B, Hsu KC (2012) HLA-C-dependent prevention of leukemia relapse by donor activating KIR2DS1. N Engl J Med 367:805-816 
Wagner I, Schefzyk D, Pruschke J, Schöfl G, Schöne B, Gruber N, Lang K, Hofmann J, Gnahm C, Hey B, Marin W, Dandekar R, Hollenbach JA, Schetelig J, Pingel J, Norman PJ, Sauter J, Schmidt AH, Lange V (2018) Allele-level KIR genotyping of more than a million samples: workflow, algorithm, and observations. Front Immunol 9:2843

Wende H, Colonna M, Ziegler A, Volz A (1999) Organization of the leukocyte receptor cluster (LRC) on human chromosome 19q13.4. Mamm Genome 10:154-160

Wilson M, Torkar M, Haude A, Milne S, Jones T, Sheer D, Beck S, Trowsdale J (2000) Plasticity in the organization and sequences of human KIR/ILT gene families. PNAS 97:4778-4783
Wright PA, (2020) Killer-cell immunoglobulin-like receptor assessment algorithms in haemopoietic progenitor cell transplantation: current perspectives and future opportunities. HLA: immune response genetics 95:435-448

Yokoyama W, Kim S (2006) Licensing of natural killer cells by self-major histocompatibility complex class I. Immunol Rev 214:143-154

Publisher's Note Springer Nature remains neutral with regard to jurisdictional claims in published maps and institutional affiliations. 